\title{
Normative Reference Equations of Airway Dynamics Assessed by Whole-Body Plethysmography During Spontaneous Breathing Transitionally Evaluated in Infants, Children and Adults
}

Richard Kraemer ( $\nabla$ richard.kraemer@hirslanden.ch )

University of Bern https://orcid.org/0000-0002-1542-2420

Hans-Jürgen Smith

Medical Development, Research Diagnostics, Berlin

Heinrich Matthys

Universitatsklinikum Freiburg

\section{Research}

Keywords: Normal reference equations, whole-body plethysmography, effective specific airway resistance, effective specific airway conductance, specific aerodynamic work of breathing

Posted Date: July 6th, 2020

DOI: https://doi.org/10.21203/rs.3.rs-39320/v1

License: (c) (1) This work is licensed under a Creative Commons Attribution 4.0 International License.

Read Full License 
3 Normative reference equations of airway dynamics

4 assessed by whole-body plethysmography during

5 spontaneous breathing transitionally evaluated in infants,

6 children and adults

(173)

Richard Kraemer ${ }^{1,2,3}$, Hans-Jürgen Smith ${ }^{4}$, and Heinrich Matthys ${ }^{5}$

\section{Addresses:}

${ }^{1}$ Department of Biomedical Research, University of Berne, CH-3005 Berne, Switzerland,

${ }^{2}$ Department of Paediatrics, University of Berne, $\mathrm{CH}-3011$ Berne, Switzerland

${ }^{3}$ Centre of Pulmonary Medicine, Hirslanden Private Hospital

Group, Salem-Hospital, Bern, Switzerland,

${ }^{3}$ Medical Development, Research in Respiratory Diagnostics, Berlin,

Germany,

${ }^{4}$ Department of Pneumology, University Hospital of Freiburg, D 79106 Freiburg, Germany

\section{E-Mails:}

Richard Kraemer - richard.kraemer@hirslanden.ch

Hans-Jürgen Smith H.Smith@arcor.de

Heinrich Matthys - Hmatthys@t-online.de

\section{Address for Correspondence:}

Prof. R. Kraemer, MD, Centre of Pulmonary Medicine, Hirslanden Private Hospital Group, Salem-Hospital, Schänzlistrasse 39, CH-3000 Bern 25, Switzerland

e-mail: richard.kraemer@hirslanden.ch

Phone: +41793002653

Fax: $\quad+41315301873$

Resp_Res_Ref_Equat_AirwMech.docx

June 18,2020 


\section{Abstract}

\section{Background}

In contrast to the conventional parameters of airway dynamics mostly obtained by the two-point approximation method, the effective specific airway resistance (sR $R_{\text {eff }}$ ), its reciprocal value the effective specific airway conductance ( $\left.s G_{\text {eff }}\right)$ resp., obtained by the integration of the entire tidal breathing loop, features promising target parameters for differentiating between individual functional disease patterns. $s R_{\text {eff }}$ can be computed as the ratio between the integral of the area enclosed by the plethysmographic shift volume-tidal flow loop, featuring the specific aerodynamic work of breathing (sWOB), and the tidal flow-volume loop, $s G_{\text {eff }}$ by the ratio of the integral of the tidal flow-volume loop and the sWOB, respectively. However, normative values for $s W O B, s R_{\text {eff }}$ and $s G_{\text {eff }}$ at resting level are not yet available.

\section{Methods}

We aimed to define reference equations in healthy infants $(n=28)$, children $(n=47)$ and adults $(n=273)$, which incorporates not only the standard anthropometric measures, but also lung volume and breathing pattern indices (including both volume and time indices). Retrospectively exported data were collected from databases of 5 Swiss lung function centres, in which plethysmography (Jaeger Würzburg, Germany) was performed using standard techniques (ATS-ERS criteria) for the assessment of airway dynamics, static lung volumes and forced breathing flow-volume loops.

\section{Results}

Using multi-linear modelling, reference equations of $s R_{\text {eff, }} s G_{\text {eff, }}$ and $s W O B$ could be defined taking as independent parameters apart from anthropometric parameters, also parameters given by the ratio between the tidal volume $\left(\mathrm{V}_{T}\right)$ and functional residual capacity $\left(F R C_{\text {pleth }}\right)$, and the ratio between $\mathrm{V}_{T}$ and inspiratory time $\left(\mathrm{V}_{\mathrm{T}} / \mathrm{T}_{\mathrm{I}}\right)$. In addition, we examined the effect of age on the breathing pattern, the relationship between breathing pattern (tidal volume) and timing (inspiratory time).

\section{Conclusions}

An alternative statistical approach to define reference equations of airway dynamics reveals that apart from the subject's anthropometric measurements, parameters of the magnitude of static lung volumes, the breathing pattern, and the timing of breathing are co-variants of reference equations of airway dynamics over a large age range. 
Reference equations of airway dynamics

Kraemer R. et al.

80

81 Keywords

82 (1) Normal reference equations; (2) whole-body plethysmography; (3) effective

83 specific airway resistance; (4) effective specific airway conductance; (5) specific 84 aerodynamic work of breathing. 


\section{Background}

Predictive equations defining reference values of lung function in infants, children and adults are usually based on the subject's anthropometric measurements, such as age, body weight, body height or a combination of the above, as independent variables and gender. Most of these regressions include linear, but also power- or quadric function relationships [1]. This may be suitable for some predictions of static lung volumes [2, 3], volume-time or flow-volume parameters [1, 4], and indices of intrapulmonary gas distribution [5-7]. A specific new approach to describe reference ranges more accurately was developed by Stanojevic et al [3], describing the relationship between spirometric lung function and height and age respectively within the paediatric age range, allowing a seamless transition to adulthood. An extension of the so called LMS (lambda, mu, sigma) method [8, 9] was applied. To our knowledge however, prediction models using LMS-statistics incorporating age and height of the subjects as independent variables have only been formulated for spirometric parameters [3]. We observed that there is a relative dearth of normative reference values measuring parameters of airway dynamics transitionally from infancy into adulthood. A first attempt at measuring airway resistance throughout the whole respiratory cycle in infants was performed by Beardsmore et al. [10], demonstrating a dynamic performance of the respiratory circuit in relation to the breathing pattern, and suggesting that expiratory looping of the resistance slope could well be due to small airway closure as previously observed by Matthys [11] in adults. Airway resistance "effectively" measured in the relation to the tidal volume was presented by Stocks et al. in the ERS/ATS task force series [12].

Normative predictive equations of airway patency, such as the effective specific airway resistance ( $\left(\mathrm{R}_{\text {eff }}\right)$ and its reciprocal value, the effective specific airway conductance ( $\mathrm{sG}_{\mathrm{eff}}$ ), as well as the specific aerodynamic work of breathing at rest (sWOB), are yet to be clearly defined. These parameters are best assessed by the plethysmographic integral method its mathematical background computing $s R_{\text {eff, }} s G_{\text {eff }}$ and sWOB previously been shown [13, 14]. More details regarding computation of parameters assessed by the integral method and a synoptical presentation how the mathematics is computed from the different breathing loops are given in the Additional File 1. This information demonstrates that the determination of sWOB is a prerequisite part of the computation of $s R_{\text {eff }}$ which is the ratio of $s W O B$ and the area of the flow-volume loop at tidal breathing. The reciprocal value of $s R_{\text {eff, }}$ the specific airway conductance $\left(\mathrm{sG}_{\text {eff }}\right.$ ), can be obtained by the integral ratio between the flow-volume loop and sWOB. 
In order to predict gender-specific normative values transitionally from infancy, through childhood into adulthood, we found it important to integrate beside anthropometric measurements, some important previously formulated findings of interrelationships in lung physiology [10-12, 15-19]. On one hand, we found it suitable to respect the disproportionate, but physiologically normal and gender-specific growth between airways and lung parenchyma, a phenomenon defined as "dysanapsis" by Green et al. [15], which may interfere defining sWOB. It is well known that there are significant male-female differences in the luminal areas of the larger central and upper central airways [18-20] which are not accounted for by differences in lung size. On the other hand our approach was conducted by the findings of Hesser et al. [17] investigating the interrelationship between endexpiratory lung volume (EELV), tidal volume $\left(\mathrm{V}_{T}\right)$, inspiratory $\left(T_{1}\right)$, and expiratory $\left(T_{E}\right)$ time during exercise in humans, demonstrating a relationship between EELV and $T_{1}$ with increasing work intensity [21] and, hence, it could well be that such interaction also play a role during tidal breathing. Although the above-mentioned observations were evaluated during exercise and different ambient conditions, we hypothesized that the pattern of breathing could significantly influence the measurements of airway dynamics at rest and be an important determinant for defining reference equations and hence normative values in humans during tidal breathing at rest. These findings of significant coherence in interrelationship between lung size and breathing characteristics under which airway dynamics are measured, prompted us to evaluate reference equations using a multi-level modelling.

The purpose of the present investigation was to define gender-specific normative reference equations of airway dynamics (sWOB, $s \mathrm{G}_{\text {eff, }}, \mathrm{sR}_{\mathrm{eff}}$ ) by an alternative approach, incorporating a) anthropometric measures (age, height, weight), potential influencing factors in relation to $b$ ) the interrelationship to static lung volumes such as total lung capacity (TLC), vital capacity (VC), $\mathrm{FRC}_{\text {pleth, }}$, and residual volume $(\mathrm{RV}), c)$ the pattern of breathing $\left(\mathrm{BF}, \mathrm{V}_{\mathrm{T}}, \mathrm{V}_{\mathrm{T}} / \mathrm{FRC}\right)$, and $d$ ) the timing of breathing $\left(T_{I}, T_{E}, V_{T} / T_{1}, V_{T} / T_{E}\right)$, in healthy infants, children and adults by multiregression models. 


\section{Material and methods}

\section{Subjects}

Plethysmographic data from healthy 38 infants (24 males, 14 females), 44 children (23 males, 21 females) and 270 adults (72 males, 198 females) were exported from 5 databases (University Children's Hospital, Berne: infants assessed by the InfantMasterLab [22, 23] children and adults assessed by the MasterLab; Lung Centre of the Hirslanden Hospital Group, Berne; Clinic of Pneumology, Cantonal Hospital St. Gallen, Switzerland, Centre of Pulmonary Medicine, Hirslanden Private Hospital Group, Zürich, Switzerland). The subjects from whom data were obtained were infants and children participating in an epidemiologic study, lab technicians, students, healthy volunteers, hospital staff, children of hospital staff, parents of children studied, and participants of lung function instruction courses. Apart from the infant whole-body plethysmograph a similar whole-body plethysmograph (both Jaeger Würzburg Germany) was used in each centre, and the exported data were obtained from the same system software (JLAB, Version 5.2).

Inclusion criteria were reproducible base-line measurements with a) an agespecific breathing frequency, $b$ ) at least 5 shift volume-tidal volume loops of comparable shapes, especially closed at zero flow points, $c$ ) closed expiratory part in the shift volume-tidal flow loops. Moreover, $d$ ) inspiratory capacity (IC) have to be within the range of normal $[4,24]$, in order to have achieved correct TLC and VC. The study was planned according to the Federal Law of Human Research, conceptualized by the Swiss Ethics Committee on Research involving humans, and approved by the Governmental Ethics Committees of the State of Berne, Zürich and St. Gallen. Master-files haven been stored and secured in the REDCap-system of the Clinical Trial Unit, Medical Faculty, University of Berne, Switzerland.

\section{Pulmonary Function Procedures}

In each centre the same procedure of lung function testing was performed. Apart from the infants, who were sedated using chloral hydrate and hence sleeping within the infant plethysmograph [22], lung function testing was performed with the patient in a seated position [25]. In a $1^{\text {st }}$ phase the assessment of airway dynamics (sWOB, $s G_{\text {eff, }}$ and $s R_{\text {eff }}$ ) was obtained during at least 8 to 10 breathing cycles of quiet breathing (no panting). In a $2^{\text {nd }}$ phase the measurement of $F R C_{\text {pleth }}$ at $E E L V$ was measured by at least 3 shutter closure manoeuvres of comparable shapes, providing reproducible FRC-volumes within a range $7 \%$, directly followed by a $3^{\text {rd }}$ phase, the 
measurements of static lung volumes such as the expiratory reserve volume, RV, VC, the IC, and hence TLC. Only in a $4^{\text {th }}$ phase at least 3 forced breathing manoeuvres were performed measuring forced expired volume in 1 second $\left(\mathrm{FEV}_{1}\right)$, forced vital capacity (FVC), maximal flows at 25\% $\left(\mathrm{FEF}_{25}\right), 50 \%\left(\mathrm{FEF}_{50}\right)$ and $75 \%$ $\left(F E F_{75}\right)$ of $F V C$, as well as the mid-flow between $25 \%$ to $75 \%$ of forced expired lung volume $\left(\mathrm{FEF}_{25-75}\right)$, assessed by standard techniques $[1,12,26]$.

\section{Airway dynamics.}

The mathematical background of the integral technique to obtain parameters of airway dynamics such as effective specific airway resistance $\left(s R_{\text {eff }}\right)$ its reciprocal values the effective specific airway conductance ( $\left(\mathrm{G}_{\text {eff }}\right)$ and the specific aerodynamic work of breathing (sWOB) during tidal breathing has been previously described [14, 27-29]. Shortly, $s \mathrm{G}_{\text {eff }}$ is computed as the ratio between the integral of the area of the tidal flow - volume loop as numerator $\left(\oint V^{\prime} d V_{T}\right)$ and the integral of the area enclosed by the specific aerodynamic work of breathing $\left(\mathrm{sWOB}=\oint \Delta V_{\text {pleth }} d V_{T}\right)$ according the equation:

(1)

$$
s G_{e f f}=\frac{1}{P_{a m b}-P_{H_{2} O}} * \frac{\oint V^{\prime} d V_{T}}{\oint \Delta V_{p l e t h} d V_{T}}=\frac{1}{s R_{e f f}}
$$

where $\left(\mathrm{P}_{\mathrm{amb}}-\mathrm{P}_{\mathrm{H} 2 \mathrm{O}}\right)$ is the dry air pressure, the integral $\oint V_{\text {pleth }} d V_{T}$ the equivalent to the area enclosed by sWOB and the integral $\oint V^{\prime} V_{T}$ the equivalent to the area of the flow-volume loop [23]. Details of the methodological and mathematical approach of the so called "integral method" are given in the Additional File 1.

For the plethysmographic measurements the median of at least 5 single plethysmographic shift volume - tidal flow loops was calculated, and for the indices of the forced breathing parameters the maximum of the 3 valid measurements was taken, as soon as the best and second-best flow-volume loops were comparable in their pattern. Pulmonary function test data of all parameters were assessed in absolute values, as percentage of predicted normal values, and z-transformed accordingly [26, 30]. The same standardized calibrations of flow, box leakage and internal box pressure were performed daily in each centre in the morning and at midday, and a so called "biological calibration" was performed monthly using a healthy technician as a biological control. 


\section{Mathematical and statistical approaches}

To define the mathematical relationship between $s W O B, s G_{\text {eff }}$ and $s R_{\text {eff }}$ as dependent parameters to be predicted, we first used the "curve estimation" tool of the SPSS for linear, logarithmic, power and exponential regressions, as well as quadratic and cubic function for age, height, and weight, as previously proposed by Hankinson et al. [1]. It turned out, that most mathematical relationships featured powerassociations. Therefore, our modelling used absolute values and their natural logarithm (In).

In a second step, we evaluated whether reference equations of $\mathrm{sWOB}, \mathrm{s} \mathrm{G}_{\text {eff }}$ und $s R_{\text {eff }}$ are gender specific. In a linear mixed model (LMM) analysis of the Statistical Package for Social Science (IBM SPSS version 25 Inc., Chicago, IL), "gender" was introduced as contextual variable in relation to $\ln (\mathrm{sWOB})$ as dependent variable and In(age) as covariate. No gender differences were found for these parameters. However, if predicting equations are computed for parameters of the breathing pattern $\left(B F, V_{T}, M V\right)$ and the timing of breathing $\left(T_{i}, T_{E}, V_{T} / T_{1}\right)$ all parameters presented gender differences with $\ln (\mathrm{age})$. Therefore, in the following multi-linear modelling "gender" was included as contextual variable and "In(age) as covariate.

In a third step a multilevel linear model with a three-level hierarchy was built up shown in Figure 1. In level 1 the gender of the subject was taken, in level 2 the 4 segments, within which LMM and the analysis of variance (ANOVA) were performed, and in level 3 the target parameters of airway dynamics (sWOB, sG $\mathrm{eff}_{\text {eff }}, \mathrm{R}_{\mathrm{eff}}$ ), for which predicting equations are computed. Within the 4 segments of level 2 potential predictors by which adequate predictive accuracy [31] was searched for as follows:

i) the anthropometric segment containing age, $\ln (\mathrm{age}), \mathrm{age}^{2}$, height, $\ln$ (height), height ${ }^{2}$, weight, $\ln$ (weight) and weight ${ }^{2}$,

ii) the segment of static lung volumes containing TLC, $\ln (\mathrm{TLC}), \mathrm{VC}, \ln (\mathrm{VC}), \mathrm{IC}$, $\operatorname{In}(\mathrm{IC}), \mathrm{FRC}_{\text {pleth }}, \operatorname{In}\left(\mathrm{FRC}_{\text {pleth }}\right), \mathrm{RV}, \operatorname{In}(\mathrm{RV}) \mathrm{FRC} \mathrm{C}_{\text {pleth }} / \mathrm{TLC}, \mathrm{IC} / \mathrm{TLC} \mathrm{RV} / \mathrm{TLC}$, and $\mathrm{V}_{\mathrm{T}} / \mathrm{FRC}_{\text {pleth, }}$

iii) the segment of the breathing pattern given by $\left.\mathrm{BF}, \ln (\mathrm{BF}), \mathrm{V}_{\mathrm{T}}, \ln \left(\mathrm{V}_{\mathrm{T}}\right), \mathrm{MV}\right)$, $\ln (\mathrm{MV})$, and

iv) the segment defining respiratory timing $T_{1}, \ln \left(T_{1}\right), T_{E}, \ln \left(T_{E}\right), T_{1} / T_{\text {tot }}, T_{E} / T_{\text {tot }}, V_{T} / T_{1}$ $\ln \left(\mathrm{V}_{\mathrm{T} / \mathrm{T}}\right), \mathrm{V}_{\mathrm{T}} / \mathrm{T}_{\mathrm{E}}, \ln \left(\mathrm{V}_{\mathrm{T} /} \mathrm{T}_{\mathrm{E}}\right)$.

The segments described refer to separate regression models in which separate categories of variables are examined and selected for their predictive ability and minimising collinearity within each segment, and then the best variables from all 
108 segments are evaluated together in a combined multiple regression model. In this

109 particular approach, we argue that a between-segment effect regarding

110 "anthropometry", "static lung volumes", "breathing pattern" and "timing of breathing"

111 refers on the prediction of the airway dynamic parameters, and hence allowing the

112 multi-level modelling on such hierarchical data looking at interference within-segment

113 and between-gender processes with respect to the target parameters sWOB, sG $\mathrm{eff}_{\text {, }}$

$114 \mathrm{sR}_{\text {eff. }}$ Multicollinearity statistics were checked by the t-statistics, and the variance

115 inflation factor (VIF) as predictor of the linear relation to the dependent variable, (VIF

116 <). The stepwise variable selection has, similarly to the forward variable selection,

117 the advantage that after a variable is entered, all variables already in the model are

118 re-examined to see if any of them meet the criteria for removal. Apart from the actual

$119 F$ change the entry criterion was a $p \leq 0.05$, for removal a $p \leq 0.10$. Applying least

120 squares (OLS) statistics, a minimum-variance mean-unbiased estimation and hence

121 prediction of firstly $\mathrm{sWOB}$, and $\mathrm{s} \mathrm{G}_{\text {eff, }}$ and $\mathrm{s} \mathrm{R}_{\text {eff }}$ could be obtained.

122 Since we are faced with the potential problem of multicollinearity, the

123 selection of parameters suitable for the final overall regressions was made based on

124 "tolerance of collinearity" defined as 1 minus $R^{2}$ and the "variance inflation factor"

125 (VIF) defined as reciprocal of the tolerance. Parameters with values of tolerance less

126 than 0.2 and values of VIF higher than 10 were considered problematic and stepwise

127 excluded. 


\section{Results}

\section{Subject characteristics}

The initial number of subjects exported from the 5 data bases, suitable according the inclusion criteria for the present study to be analysed in a common merged database was 491 . The screening regarding internal consistency and potential error values revealed that $4.7 \%$ of the measurements of static lung volumes had either $\mathrm{FRC}_{\text {pleth, }}$, TLC, or IC beyond or above 2 standard deviations (SD) suggesting that these were measured incorrectly, mostly due to insufficient subject cooperation. In $18.8 \%$ the recoding of the $\mathrm{FEV}_{1}$, or $\mathrm{FEF}_{25-75}$ were out of the $2-\mathrm{SD}$-range. In another $4.2 \%$ of measurements the indices of timing $\left(T_{1} / T_{E}, T_{1} / T_{\text {tot }}\right)$ presented incomprehensible data, and finally in $5.4 \%$ of measurements sWOB data were either recorded, measured, or calculated erroneously. In total, $28.1 \%$ of measurements were judged unsuitable for further evaluation.

The study collective, therefore, consisted of 352 measurement sets $(71.7 \%$ of all initially exported) including 38 infants (24 males, 14 females), 44 children (23 males, 21 females) and 270 adults (72 males, 198 females). There were slightly more female subjects than males (females, mostly hospital staff members, were more easily recruited for such analysis than males). Apart from the infants and children, the age-distributions in the centres were similar. Regarding the functional characteristics of these subjects all z-scores of the parameters of the static volumes, or those obtained by forced breathing manoeuvres, were within the range of $\pm 2 S D$.

\section{Pattern of breathing and timing}

The breathing pattern and timing of breathing transitionally evaluated from infancy, over childhood into adulthood was evaluated for several parameters $\left(B F, V_{T}, M V, T_{1}\right.$, $\left.T_{E}, V_{T} / T_{1}\right)$, and summarized in Figure 2. Regression equations are given for each parameter and predicted values of these complex equations are plotted to visualise the predicted relationship. The BF decreased from $37.9 \pm 7.2$ breaths per minute in infancy to $20.3 \pm 3.2$ breaths per minute during childhood remaining at $20.2 \pm 3.2$ breaths per minute during adulthood. Conversely, $\mathrm{V}_{\mathrm{T}}$ increased gradually from $0.108 \pm 0.037 \mathrm{~L}$ in infancy to $0.65 \pm 0.121 \mathrm{~L}$ during childhood to $0.900 \pm 0.084 \mathrm{~L}$ in adulthood. Similar changes were also found for the timing $T_{1}$ which increased from $0.672 \pm 0.088 \mathrm{sec}$ during infancy, to $1.271 \pm 0.106 \mathrm{sec}$ during childhood, and remained at $1.295 \pm 0.119 \mathrm{sec}$ at adulthood. Similarly, also $T_{E}$ increased from $0.979 \pm 0.126 \mathrm{sec}$ to $1.420 \pm 0.159 \mathrm{sec}$ during childhood, $1.656 \pm 0.205 \mathrm{sec}$, during adulthood resp.

37 Combining the breathing pattern with the timing of breathing showed, that $V_{T} / T_{1}$ 
increased from $0.157 \mathrm{~L} / \mathrm{sec}$ to $0.553 \pm 0.091 \mathrm{~L} / \mathrm{sec}$ during childhood to $0.693 \pm 0.063$ L/sec during adulthood.

In analogy to Hesser's Figure 5 [17] showing good correlations between $\mathrm{V}_{\mathrm{T}}$ and isopleths for different $\mathrm{V}_{\mathrm{T}} / \mathrm{T}_{1}$ during exercise, we can demonstrate, that similarly significant regressions between $V_{T}$ and $T_{\text {I }}$ are related within quartiles of $V_{T} / T_{1}$ at rest with tidal breathing. Figure 3 shows that as $T_{1}$ increased from infancy to adulthood, $V_{T}$ increased within the three $V_{T} / T_{1}$ quartiles The linear regressions between $T_{1}$ and $V_{T} / T_{1}$ were significantly different $(p<0.001)$ with slopes of $0.322 \pm 0.047,0.708 \pm 0.058$ and $0.584 \pm 0.044$ within the $V_{T} / T_{1}$ quartiles $P_{<25}, P_{25-75}$ and $P_{>75}$, respectively. Quartiles were chosen in order to quantify the ratio of $\mathrm{V}_{T} / \mathrm{T}_{1}$ to which no values predicted are available. Based on these and previous observations that the threshold of the inspiratory off-switch mechanisms depends on central inspiratory activity [32], which in turn increases with airway resistance [33], we hypothesised that the volumetric and timing indices of ventilation could well influence the measurements of airway dynamics even at rest, and hence should be respected when defining normative values und predictive equations in humans over all age ranges. This remarkable coherence of interrelationships between breathing characteristics and timing of breathing prompted us to study the parameters of lung dynamics sWOB, sG $\mathrm{eff}_{\text {ff }}$ and $s R_{\text {eff }}$ at rest, in relation to different parameters defining respiratory output, the breathing pattern, and the EELV, under which conditions these parameters are measured [12].

\section{Normative equations of airway dynamics evaluated by a multilevel linear model}

The procedure of stepwise exclusion of parameters within the 4 segments was performed as follows:

$1^{\text {st }}$ segment: sWOB in relation to parameters of "anthropometry" sWOB $=\operatorname{EXP}\left(-16.657+.018^{*}\right.$ Gender $+.257^{*} \ln ($ age $)+3.288^{*} \ln$ (height) $-3.807 E-5^{*}$ height $\left.^{2}\right) \pm .143071$ (SEE); male $=0$; female $=1$ excluded: age, age $^{2}$, height, height ${ }^{2}$ (F-value: $3837, p<0.0001$; accuracy: $97.3 \%$ ).

$2^{\text {nd }}$ segment: sWOB in relation to "static lung volumes and $V_{T}$ at $E E L V$ " sWOB $=\operatorname{EXP}\left(-.452+.009^{*}\right.$ Gender $+.144^{*} \ln ($ age $)+1.096^{*} \ln \left(\mathrm{FRC}_{\text {pleth }}\right)$ $+0.980 * \ln \left(\mathrm{V}_{\mathrm{T}} / \mathrm{FRC}\right.$ pleth $\left.)\right) \pm .113399(\mathrm{SEE})$; male $=0$; female $=1$ excluded: $F R C_{\text {pleth }}, F R C_{\text {pleth }} / T L C$ ( $F$-value: 6160, $p<0.0001$; accuracy: $97.2 \%)$. 
76

\section{$3^{\text {rd }}$ segment:} sWOB in relation to parameters of "breathing pattern" $\mathrm{sWOB}=\mathrm{EXP}\left(-1.124+.001^{*}\right.$ Gender $+.133^{*} \ln ($ age $\left.)+1.221{ }^{*} \ln (\mathrm{VT})+.293^{*} \ln (\mathrm{BF})\right)$ \pm .106902 (SEE); male $=0$; female $=1$ excluded: $\mathrm{BF}, \mathrm{V}_{\mathrm{T}}, \mathrm{MV}, \ln (\mathrm{MV})$ ( $F$-value: 6943, $p<0.0001$; accuracy: 98.1\%).

$4^{\text {th }}$ segment: sWOB in relation to parameters of "timing of breathing" $\mathrm{sWOB}=\operatorname{EXP}\left(-.222+.012^{*}\right.$ Gender $+.151^{*} \ln ($ Age $)+1.218^{*} \ln \left(\mathrm{V}_{\mathrm{T}} / \mathrm{T}_{\mathrm{I}}\right)$ $\left.+.817^{*} \ln \left(T_{1}\right)\right) \pm .109582(\mathrm{SEE}) ;$ male $=0$; female $=1$ excluded: $T_{E}, \ln \left(T_{E}\right), V_{T} / T_{E}, \ln \left(V_{T} / T_{E}\right), V_{T} / T_{1}, T_{1}$ ( $F$-value: 6493, $p<0.0001$; accuracy: 96.2\%).

In a final step, sWOB was predicted by summarizing all selected, potentially dependent parameters and combining the 4 segments of the model. Assessing the "best" model for the data using marginal $t$-tests for random effects and hence avoiding collinearity, we utilized the marginal test by using primary forward, and checking by backward selection. Once we identified the parameters with the smallest marginal $P$ values $(<0.05)$ and good tolerance as well as VIF, we trimmed the identified parameters, selected from each model to a final equation, which was again regressed to the most significant parameters. From this combined model the regression equations $( \pm S E E)$ for SWOB $\left(k P a^{*} L^{*} L\right)$ then were as follows:

$$
\begin{aligned}
& \text { sWOB }=\text { EXP }\left(-.300+.017^{*} \text { gender+.138* } \ln (\text { age })+.836^{*} \ln \left(\mathrm{FRC}_{\text {pleth }}\right)\right. \\
& \left.\left.+.744^{*} \ln \left(\mathrm{V}_{\mathrm{T}} / \mathrm{FRC} \mathrm{C}_{\text {pleth }}\right)+.387^{*} \ln \left(\mathrm{V}_{\mathrm{T}} / \mathrm{T}_{\mathrm{I}}\right) \pm .109083\right)\right)(\mathrm{SEE}) \\
& { }^{*} \text { gender: male }=0 ; \text { female }=1(F \text {-value: } 5332, p<0.0001 ; \text { accuracy: } 97.3 \%)
\end{aligned}
$$

Accordingly, also $s \mathrm{G}_{\text {eff }}$ and $s \mathrm{R}_{\text {eff }}$ can be defined, using the same multi-level models. We found for each two gender-specific equations, one based on significantly predicting parameters only, and one including sWOB as follows:

$$
\begin{aligned}
& s G_{\text {eff }}=\operatorname{EXP}\left(.816-.050 * \text { gender }-.423^{*} \ln (\mathrm{sWOB})+.415^{*} \ln \left(\mathrm{FRC}_{\text {pleth }}\right)\right. \\
& \left.+.603^{*} \ln \left(\mathrm{V}_{\mathrm{T}} / \mathrm{FRC} \mathrm{Cleth}_{\text {ple }}\right)\right) \pm .12781 \text { (SEE) } \\
& \text { *gender: male }=0 \text {; female }=1(F \text {-value: } 134.1, p<0.0001 \text {; accuracy: } 53.8 \%) \\
& \mathbf{s R}_{\text {eff }}=\operatorname{EXP}\left(-.816+.050^{*} \text { gender }+.423^{*} \ln (\mathrm{sWOB})-.415^{*} \ln \left(\mathrm{FRC}_{\text {pleth }}\right)\right. \\
& -.603^{*} \ln \left(\mathrm{V}_{\mathrm{T}} / \mathrm{FRC}_{\text {pleth }}\right) \pm .12781 \text { (SEE) } \\
& \text { *gender: } \text { male }=0 \text {; female }=1 \text { ( } F \text {-value: } 134.1, p<0.0001 \text {; accuracy: } 53.8 \% \text { ) }
\end{aligned}
$$

This evaluation suggests, that predictions of airway dynamic parameters should be performed by a multi-level model, considering not only anthropometric 
119 parameters, but also the $E E R L$ at $F R C$, the breathing pattern $\left(\mathrm{V}_{\mathrm{T}} / \mathrm{FRC}\right)$ and the

120 timing of breathing $\left(\mathrm{V}_{\mathrm{T}} / \mathrm{T}_{\mathrm{I}}\right)$. Nontheory, in the reference equations of sGeff and sReff

121 age and $\mathrm{V}_{\mathrm{T}} / \mathrm{T}_{\text {I }}$ are no longer included, because they are incorporated in sWOB. 


\section{Discussion}

\section{Findings of the present study}

4 The relationship between parameters of airway dynamics and anthropometric measurements seems to be very complex, and only a few reference values are available $[12,25,34]$. The major mathematical component of the equations defining $s G_{\text {eff }}$ and/or $s R_{\text {eff }}$ is $s W O B$, given by the integral of the plethysmographic shift volume versus its tidal volume loop $\left(\oint \Delta \mathrm{V}_{\text {pleth }} \mathrm{dV}_{\mathrm{T}}\right)$. In our perception, this plethysmographic parameter, expressing the specific aerodynamic work of breathing at rest, has not yet reached enough attention so far. We found that sWOB depends gender-specifically and multilinearly as a power function in addition to age, also upon FRC, the breathing pattern $\left(\mathrm{V}_{T} / \mathrm{FRC}\right)$ and the respiratory timing $\left(\mathrm{V}_{\mathrm{T}} / \mathrm{T}_{\mathrm{I}}\right)$. Most important, this kind of modelling has shown to be predictive for a large age range beginning in infancy, through childhood into adulthood.

The present study reveals some important advantages of measuring airway dynamics by whole-body plethysmography in so far as the estimation of the degree of airway patency is closely measured in relation to the actual EELV at FRC, which may be important, if the EELV is altered in patients with lung disease. This is important in the assessment of the entire understanding of how airway dynamics behave in relation to the distending forces of the thoraco-pulmonary system, especially in diseased subjects with pulmonary hyperinflation, small airway dysfunction and/or pulmonary restriction. Likewise, with other measurement techniques plethysmographic measurements can be performed during tidal breathing, requiring little cooperation from the subject and therefore, are quasi effort independent. Moreover, deep inspiration and forced breathing manoeuvres influencing regional distribution of the air and changes the so called "volume history" [35-37] are not needed, and such side-effect can be avoided.

\section{Paradigm-change expressing airway dynamics}

A major step in the assessment of airway dynamics throughout the entire plethysmographic shift volume - tidal flow loop and its mathematical comprehension of loop shaping, was initially elaborated and introduced by Matthys and Orth [29], defining the so call effective specific airway resistance $s R_{\text {eff. }}$ The aim of this initial approach shortly coming up after the report of Islam and UImer [38], was to analyse the contribution of these pathophysiological disturbances to a dissociation between maximal shift volume and maximal flow. They extended the dimensional analysis applied by Jaeger and Otis [39] to integrate these contributions to an "effective 
resistance" that included the effects of the entire range of variable flows during tidal breathing and nonlinearities in the breathing loop. The outstanding characteristic of $s G_{\text {eff, }} s R_{\text {eff }}$ respectively is its reflection of an integrative assessment of airway behaviour throughout the entire tidal breathing cycles. Digital integration of the respective loops improves the signal-to-noise ratio.

The specific work of breathing (sWOB) can be considered as an approximation of the total gas-dynamic (impedance) work performed during a breathing cycle [40]. The energy requirement for normal resting breathing takes only a small fraction of the basal metabolism in healthy subjects, but may be of considerable magnitude in patients with obstructive pulmonary diseases [41]. There are two components of the work of breathing during respiration: the flowaerodynamic work of breathing and the elastic work of breathing. Flow-aerodynamic work refers to the work to overcome the frictional resistance to gas flow due to compression and decompression within the ventilated airways and the elastic components for tissue movement, whereas elastic work overcomes the elastic recoil during inhalation storing energy to be recovered during expiration. Both, flowresistive and elastic work are conducted during inspiration and expiration. Classically, it may be computed in terms of oesophageal pressure multiplied by the change in pulmonary volume.

Although the oesophageal pressure measurement remains the solid reference technique to completely quantitate the efforts of breathing to move the lung, whole-body plethysmography allows estimation of the gas-dynamic, resistive effort by referring the integral of the plethysmographic shift-volume, and hence the intra-plethysmographic pressure changes, to the integral of the tidal volume. In a constant volume whole-body plethysmograph, the shift volume refers to the magnitude of lung volume which fades away in compression and originates in decompression and which is proportional to the airway resistance and the absolute, ventilated and non-ventilated lung volumes. It follows that the specific gas-dynamic work performed during resting tidal breathing can be estimated by simultaneous assessment of the plethysmographic shift-volume and the corresponding tidal volume (Figure 1B).

Complexity defining prediction equations for airway dynamics. Airway resistance in humans increases as a power function of flow, and in close proportion to the square root of density $[42,43]$. Previous work has shown that airway resistance is highly dependent upon the breathing pattern and the EELV at FRC, at least during exercise [17]. It was well demonstrated in the 1980's and 1990's that 
there is a significant relationship between the pattern of breathing and airway resistance during exercise, and that the threshold of the so called inspiratory offswitch mechanisms must be taken into account with the central inspiratory activity $[17,44]$. The pattern of breathing and airway resistance during exercise in terms of the relationships of inspiratory time $\left(T_{1}\right)$, the tidal volume $\left(V_{T}\right)$ and to EELV was extensively studied by Hesser and Lind [17, 21, 45], showing the interrelationship between $T_{1}$, and $V_{T}$ in different ranges. Our analyses (Figure 3 ) demonstrate that such interrelationships play also a role during tidal breathing, a physiologic argument to have such parameters included in the predicting equations.

The multi-level factor approach defining the reference values of airway dynamics in healthy subjects transitionally assessed over a large age-range, could lead to a certain paradigm change, especially what dynamic tests are concerned. The assessment of bronchodilator response (BDR) on one hand, and the assessment of airway hyperreactivity (AHR) by methacholine challenge test (MCT) on the other hand [46], are important diagnostic tools to differentiate various diagnostic groups such as asthma, cystic fibrosis, chronic obstructive pulmonary disease, asthma-COPD-overlap and idiopathic pulmonary fibrosis amongst others. Both test-procedures - BDR and MCT - are principally based on defining airway patency, and hence changes of airway dynamics during these test procedures. Therefore, we wish to emphasise that regarding BDR, and thus reversibility of airway obstruction, or MCT, and accordingly the diagnostic tool for AHR, the specific aerodynamic work of breathing could well be a new reliable parameter to define specific disease endo-phenotypes.

\section{Conclusion}

There are many advantages using the plethysmographic parameters (sWOB, sG $\mathrm{eff}_{\text {, }}$ $s R_{\text {eff, }}$, obtained by the integral method over the whole range of the breathing cycle as objective target parameters of airway dynamics. Transitorily applied over the whole age-range from infancy to adulthood by the present work, the gap in accurate regression equations to obtain individual normative data can be filled. Prospectively designed future studies will show the potential for discernment offered by these target parameters. A further challenge will be to facilitate more standardized measurements of airway dynamics in infant whole-body plethysmography by the implementation of an accurate electronic thermal compensation, offering the opportunity to access lung disease in the earliest phase. 
1.

\section{REFERENCES} Hankinson JL, Odencrantz JR, Fedan KB: Spirometric reference values from a sample of the general U.S. population. Am J Respir Crit Care Med 1999, 159:179-187.

Quanjer PH, Hall GL, Stanojevic S, Cole TJ, Stocks J: Age- and height-based prediction bias in spirometry reference equations. Eur Respir J 2012, 40:190-197.

Quanjer PH, Stanojevic S, Cole TJ, Baur X, Hall GL, Culver BH, Enright PL, Hankinson JL, Ip MS, Zheng J, et al: Multi-ethnic reference values for spirometry for the 3-95-yr age range: the global lung function 2012 equations. Eur Respir J 2012, 40:1324-1343.

Quanjer PH, Tammeling GJ, Cotes JE, Pedersen OF, Peslin R, Yernault JC: Lung volumes and foreced ventilatory flows. Eur Respir J 1993, Suppl. 16:5-40.

Kraemer R, Zehnder M, Meister B: Intrapulmonary gas distribution in healthy children. Respir Physiol 1986, 65:127-137.

Lum S, Stocks J, Stanojevic S, Wade A, Robinson P, Gustafsson P, Brown M, Aurora $P$, Subbarao $P$, Hoo AF, Sonnappa S: Age and height dependence of lung clearance index and functional residual capacity. Eur Respir J 2013, 41:1371-1377.

Kraemer R, Meister B: Fast real-time moment-ratio analysis of multibreath nitrogen washout in children. J Appl Physiol 1985, 59:1137-1144.

Cole TJ, Green PJ: Smoothing reference centile curves: the LMS method and penalized likelihood. Stat Med 1992, 11:1305-1319.

Cole TJ, Stanojevic S, Stocks J, Coates AL, Hankinson JL, Wade AM: Ageand size-related reference ranges: a case study of spirometry through childhood and adulthood. Stat Med 2009, 28:880-898.

Beardsmore CS, Godfrey S, Shani N, Maayan C, Bar-Yishay E: Airway resistance measurements throughout the respiratory cycle in infants. Respiration 1986, 49:81-93.

Matthys $\mathrm{H}$ : The assessment of airways obstruction. Bull Physiopathol Respir (Nancy) 1973, 9:961-978.

Stocks J, Godfrey S, Beardsmore C, Bar-Yishay E, Castile R: Plethysmographic measurements of lung volume and airway resistance. ERS/ATS Task Force on Standards for Infant Respiratory Function Testing. European Respiratory Society/ American Thoracic Society. Eur Respir J 2001, 17:302-312.

Kraemer R, Blum A, Schibler A, Ammann RA, Gallati S: Ventilation inhomogeneities in relation to standard lung function in patients with cystic fibrosis. Am J Respir Crit Care Med 2005, 171:371-378.

Kraemer R, Delosea N, Ballinari P, Gallati S, Crameri R: Effect of allergic bronchopulmonary aspergillosis on lung function in children with cystic fibrosis. Am J Respir Crit Care Med 2006, 174:1211-1220. 
15.

16.

17.

18.

19.

20.

21.

22.

23.

24.

25.

26.

27.

28.

29.

30.

Green M, Mead J, Turner JM: Variability of maximum expiratory flowvolume curves. J Appl Physiol 1974, 37:67-74.

Dominelli PB, Molgat-Seon Y, Bingham D, Swartz PM, Road JD, Foster GE, Sheel AW: Dysanapsis and the resistive work of breathing during exercise in healthy men and women. $J$ Appl Physiol (1985) 2015, 119:1105-1113.

Hesser CM, Lind F, Linnarsson D: Significance of airway resistance for the pattern of breathing and lung volumes in exercising humans. $J \mathrm{Appl}$ Physiol (1985) 1990, 68:1875-1882.

Sheel AW, Guenette JA, Yuan R, Holy L, Mayo JR, McWilliams AM, Lam S, Coxson HO: Evidence for dysanapsis using computed tomographic imaging of the airways in older ex-smokers. J Appl Physiol (1985) 2009, 107:1622-1628.

Mead J: Dysanapsis in normal lungs assessed by the relationship between maximal flow, static recoil, and vital capacity. Am Rev Respir Dis 1980, 121:339-342.

Jaeger MJ, Matthys $\mathrm{H}$ : The pattern of flow in the upper human airways. Respir Physiol 1968, 6:113-127.

Lind $\mathrm{F}$, Hesser $\mathrm{CM}$ : Breathing pattern and occlusion pressure during moderate and heavy exercise. Acta Physiol Scand 1984, 122:61-69.

Kraemer R: Whole-body plethysmography in the clinical assessment of infants with bronchopulmonary diseases. Respiration 1993, 60:1-8.

Jackson AC, Tennhoff W, Kraemer R, Frey U: Airway and tissue resistance in wheezy infants: effects of albuterol. Am J Respir Crit Care Med 1999, 160:557-563.

Zapletal A, Samanek M, Paul T: Lung function in children and adolescents. Basel (Switzerland): Karger; 1987.

Goldman M, Smith HJ, Ulmer WT: Lung function testing: Whole-body plethysmography. Eur Respir Mon 2005, 31:15-43.

Pellegrino R, Viegi G, Brusasco V, Crapo RO, Burgos F, Casaburi R, Coates A, van der Grinten CP, Gustafsson P, Hankinson J, et al: Interpretative strategies for lung function tests. Eur Respir J 2005, 26:948-968.

Kraemer R, Baldwin DN, Ammann RA, Frey U, Gallati S: Progression of pulmonary hyperinflation and trapped gas associated with genetic and environmental factors in children with cystic fibrosis. Respir Res 2006, 7:138.

Kraemer R, Smith H-J, Sigrist T, Giger G, Keller R, Frey M: Diagnostic Accuracy of Methacholine Challenge Tests assessing Airway Hyperreactivity in Asthmatic Patients - a multifunctional Approach. Respir Res 2016, 17):154-.

Matthys $\mathrm{H}$, Orth $\mathrm{U}$ : Comparative measurements of airway resistance. Respiration 1975, 32:121-134.

Stocks J, Quanjer PH: Reference values for residual volume, functional residual capacity and total lung capacity. ATS Workshop on Lung Volume 
31.

34.

35.

36.

38.

40.

42.

43.

44.

46.
Measurements. Official Statement of The European Respiratory Society. Eur Respir J 1995, 8:492-506.

Yang HB: Introducing the automatic linear modeling (LINEAR) procedure in SPSS statisticsc. Multiple Linear Regression Viewpoints 2013, 39(2):27-37.

32. von Euler $\mathrm{C}$ : On the central pattern generator for the basic breathing rhythmicity. J Appl Physiol Respir Environ Exerc Physiol 1983, 55:1647-1659.

33. Hesser CM, Lind F: Role of airway resistance in the control of ventilation during exercise. Acta Physiol Scand 1984, 120:557-565. Criee CP, Sorichter S, Smith HJ, Kardos P, Merget R, Heise D, Berdel D, Kohler D, Magnussen $\mathrm{H}$, Marek W, et al: Body plethysmography--its principles and clinical use. Respir Med 2011, 105:959-971.

Agostoni E, Mead, J.: Statics of the respiratory system. In Handbook of Physiology. American Physiological Society, Washington D.C. edition. Edited by Fenn WO, Rahn, H. ; 1964: 411-427

Mead J, Turner JM, Macklem PT, Little JB: Significance of the relationship between lung recoil and maximum expiratory flow. J Appl Physiol 1967, 22:95-108.

Duggan CJ, Castle WD, Berend N: Effects of continuous positive airway pressure breathing on lung volume and distensibility. $J$ Appl Physiol (1985) 1990, 68:1121-1126. Islam MS, Ulmer WT: Diagnostic value of "closing volume" in comparison to "airway resistance-lung volume plot". Respiration 1974, 31:449-458. Jaeger MJ, Otis AB: Measurement of Airway Resistance with a Volume Displacement Body Plethysmograph. J Appl Physiol 1964, 19:813-820. Matthys $\mathrm{H}$, Overrath $\mathrm{G}$ : Dynamics of gas and work of breathing in obstructive lung disease. Bull Physiopathol Respir (Nancy) 1971, 7:457-466.

Otis AB: The work of breathing. Physiol Rev 1954, 34:449-458. Maio DA, Farhi LE: Effect of gas density on mechanics of breathing. $J$ App/ Physiol 1967, 23:687-693.

Pedley TJ, Schroter RC, Sudlow MF: The prediction of pressure drop and variation of resistance within the human bronchial airways. Respir Physiol 1970, 9:387-405.

Hesser CM, Holmgren B: Effects of raised barometric pressures on respiration in man. Acta Physiol Scand 1959, 47:28-43.

45. Lind $\mathrm{F}$, Hesser $\mathrm{CM}$ : Breathing pattern and lung volumes during exercise. Acta Physiol Scand 1984, 120:123-129. Kraemer R, Smith HJ, Sigrist T, Giger G, Keller R, Frey M: Diagnostic accuracy of methacholine challenge tests assessing airway hyperreactivity in asthmatic patients - a multifunctional approach. Respir Res 2016, 17:154. 


\section{Availability of data and materials}

130 The datasets used and/or analysed during the current study are available from the

131 corresponding author on reasonable request.

132

133

134

\section{Abbreviations}

135

136 AHR airway hyperreactivity

137 ATS American Thoracic Society

138 BF breathing frequency

139 BRD bronchodilator response

$140 \Delta \mathrm{V}_{\text {pleth }} \quad$ change of plethysmographic shift volume

141 EELV end-expiratory lung volume

142 ERS European Respiratory Society

$143 \mathrm{FEF}_{25-75}$ forced expiratory flow between 25 and $75 \%$ vital capacity

$144 \mathrm{FEF}_{50} \quad$ forced expiratory flow at $50 \%$ of vital capacity

$145 \mathrm{FEV}_{1} \quad$ forced expiratory volume in 1 second

$146 \mathrm{FRC}_{\text {pleth }} \quad$ plethysmographic functional residual capacity

147 FVC forced vital capacity

148 IC inspiratory capacity

149 LMM linear mixed model

150 Ln natural logarithm

151 MCT methacholine challenge test

152 MV minute ventilation

153 OLS ordinary least square

$154 \mathrm{P}_{\mathrm{amb}} \quad$ barometric pressure

$155 \mathrm{P}_{\mathrm{H} 2 \mathrm{O}} \quad$ saturated vapor water pressure

$156 \mathrm{R}_{\text {int }} \quad$ interruptor resistance

157 RV residual volume

158 SD standard deviation

159 sGaw specific airway conductance

$160 \mathrm{sG}_{\text {eff }} \quad$ effective specific airway conductance

$161 \mathrm{sR}_{\text {eff }} \quad$ effective specific airway resistance

162 sWOB effective resistive work of breathing

$163 \mathrm{~T}_{E} \quad$ expiratory time

$164 \mathrm{~T}_{1} \quad$ inspiratory time

165 TLC total lung capacity 


$\begin{array}{lll}166 & V^{\prime} & \text { flow } \\ 167 & V_{\text {box }} & \text { volume of the plethysmographic box } \\ 168 & \text { VC } & \text { Vital capacity } \\ 169 & \text { VIF } & \text { variance inflation factor } \\ 170 & V_{T} & \text { tidal volume }\end{array}$

\section{Declarations}

\section{Ethics approval and consent to participate}

175 The study was planned according to the Federal Law of Human Research,

176 conceptualized by the Swiss Ethics Committee on Research involving humans, and

177 approved by the Governmental Ethics Committees of the State of Berne, Zürich and

178 St. Gallen. Master-files haven been stored and secured in the REDCap-system of the

179 Clinical Trial Unit, Medical Faculty, University of Berne, Switzerland.

\section{Consent for publication}

182 Not applicable (retrospective evaluation of lung function data)

183

\section{Availability of data and material}

185 Master-files haven been stored and secured in the REDCap-system of the Clinical

186 Trial Unit, Medical Faculty, University of Berne, Switzerland.

\section{Funding}

189 No funding sources

\section{Competing interests}

192 All authors have no competing interests to declare.

\section{Contributions}

195 RK designed, coordinated and analysed the data, and drafted the manuscript. H-JS

196 gave advice in the technical parts of the data acquisition and took part in the

197 interpretation of data and revising, and HM edited and revised the manuscript. All

198 authors approved the final version of the manuscript.

\section{Acknowledgments}

201 We thank all the participants, the parents of infants and children, and the technicians 
202 who volunteered for lung function testing diligently devoting their time. We would also 203 like to thank Sabina Gallati from the Division of Human Genetics, University of Berne 204 for the critical reviews of the manuscripts and Mrs. Zoe Clerc, Laboratory Technician, 205 Division of Human Genetics, University of Berne for reviewing the English style of the 206 manuscript.

207

208 Competing interests

209 The authors declare that they have no competing interests.

210 Supplementary information

211 Additional file 1

212 Additional file 2

213 Additional file 3 


\section{Legend to figures}

\section{Figure 1.}

Modified print-screen, originally depicted from the Jaeger infant whole-body plethysmograph, showing breath-by-breath tracings from which the effective specific airway resistance ( $s R_{\text {eff }}$ ), its reciprocal value of the effective specific airway conductance ( $\left(\mathrm{G}_{\text {eff }}\right)$ can be computed, using the integral of the tidal flow-volume area (A) and the integral of the plethysmographic shift-volume versus tidal volume area (B), the latter representing the specific aerodynamic work of breathing (sWOB), the crossbar and zero-flow point demonstrating BTPS conditions. $\left.\mathrm{sR}_{\text {eff }}\right)$ and its reciprocal value, $s G_{\text {eff }}$ are computed by the integration of sWOB in relation to the tidal flowvolume loop $(\mathrm{C})$.

\section{Figure 2.}

The breathing pattern and timing of breathing transitionally evaluated from infancy, over childhood into adulthood featuring normative predictive equations for the breathing frequency $(\mathrm{BF})$, tidal volume at end-expiratory level $\left(\mathrm{V}_{\mathrm{T}}\right)$, minute ventilation (MV), inspiratory time $\left(T_{1}\right)$, expiratory time $\left(T_{E}\right)$, and the ratio between $V_{T}$ and $T_{1}$ $\left(\mathrm{V}_{\mathrm{T}} / \mathrm{T}_{\mathrm{l}}\right)$.

\section{Figure 3.}

Tidal volume $\left(\mathrm{V}_{T}\right)$ as function of inspiratory time $\left(\mathrm{T}_{1}\right)$ within quartiles of $\mathrm{V}_{T} / \mathrm{T}_{\text {I }}$ at rest.

\section{Figure 4.}

Relationship between the dysanapsis-ratios $\mathrm{FEF}_{25-75} / \mathrm{FVC}$ to age (Figure 4A) showing a lower dysanapsis-ratio in females than males after the age of 17.5 years. Similarly, sWOB (Figure 4B) showing a dissociation between males and females, with lower sWOB in females than males after the age of 15.4 years.

\section{Figure 5.}

Dysanapsis given by the dysanapsis-ratio $\left(\mathrm{FEF}_{25-75} / \mathrm{FVC}\right)$ in relation to $\mathrm{FRC}_{\text {pleth }}$ (Figure 5A) and given by the specific aerodynamic work of breathing (sWOB; Figure5B) both at rest and stratified by gender. 


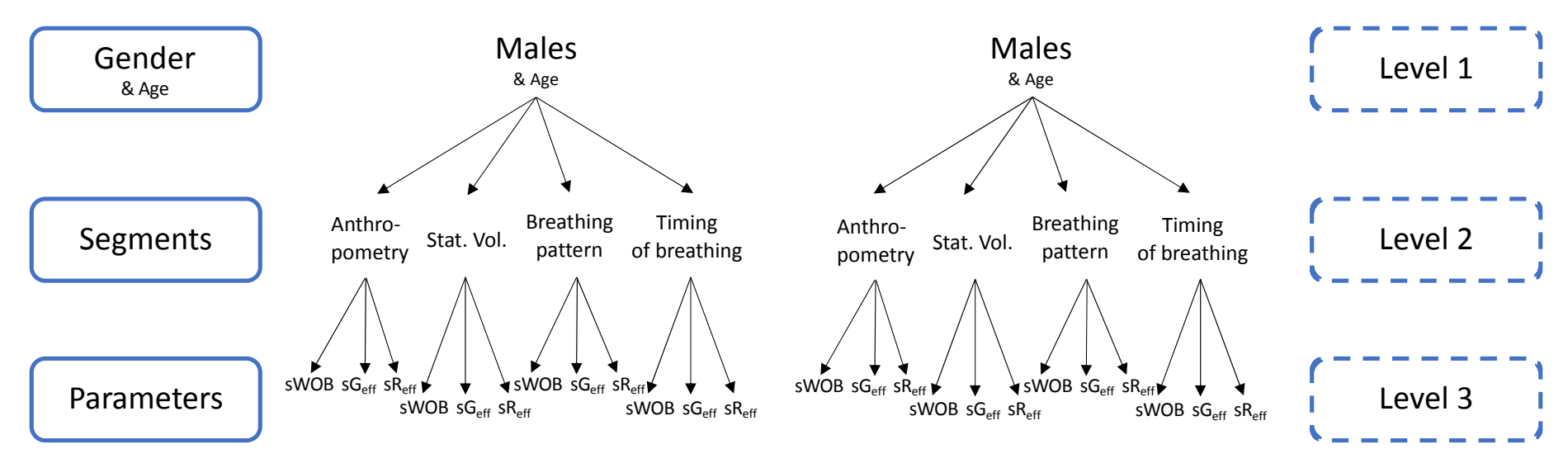

Figure 1 

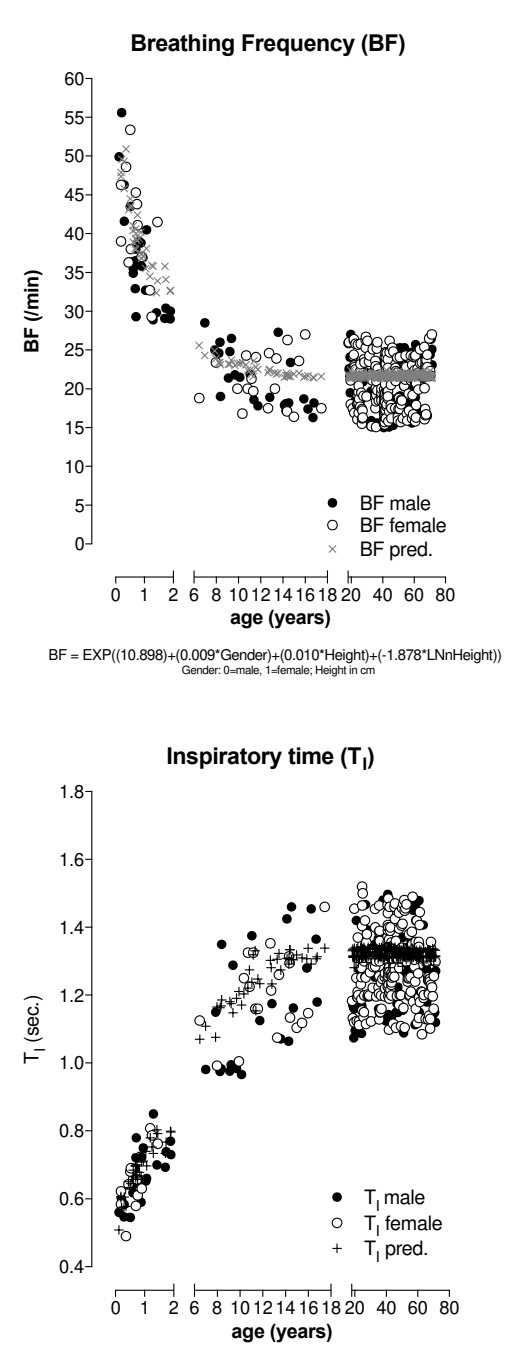

Fig. 2
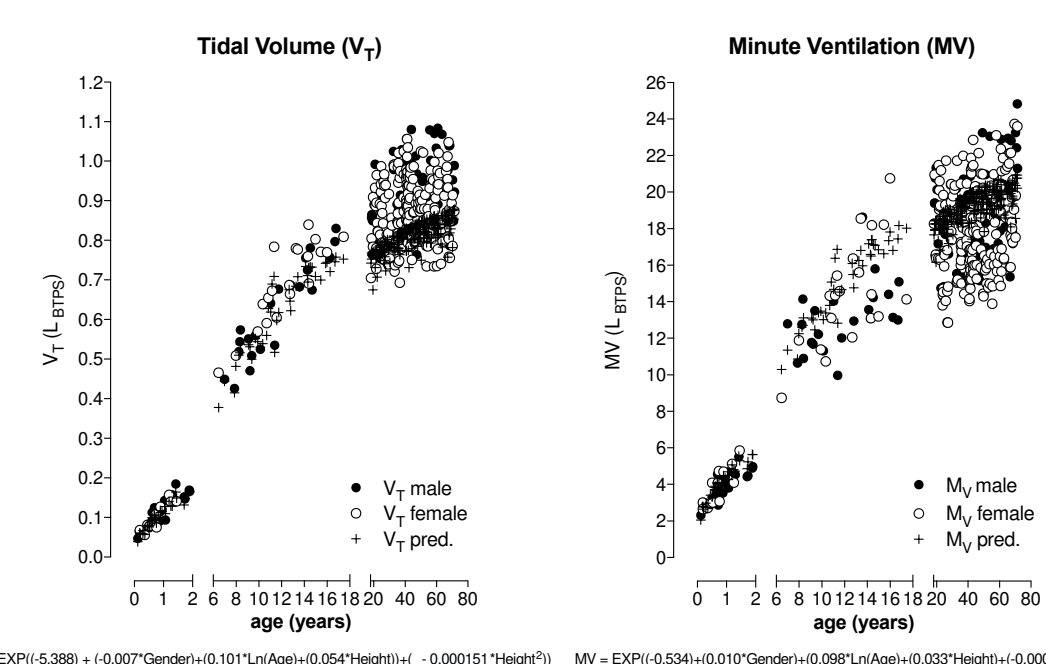

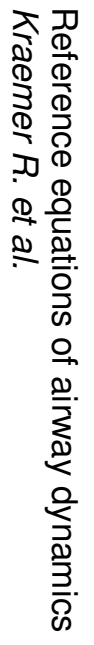

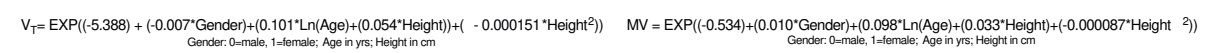
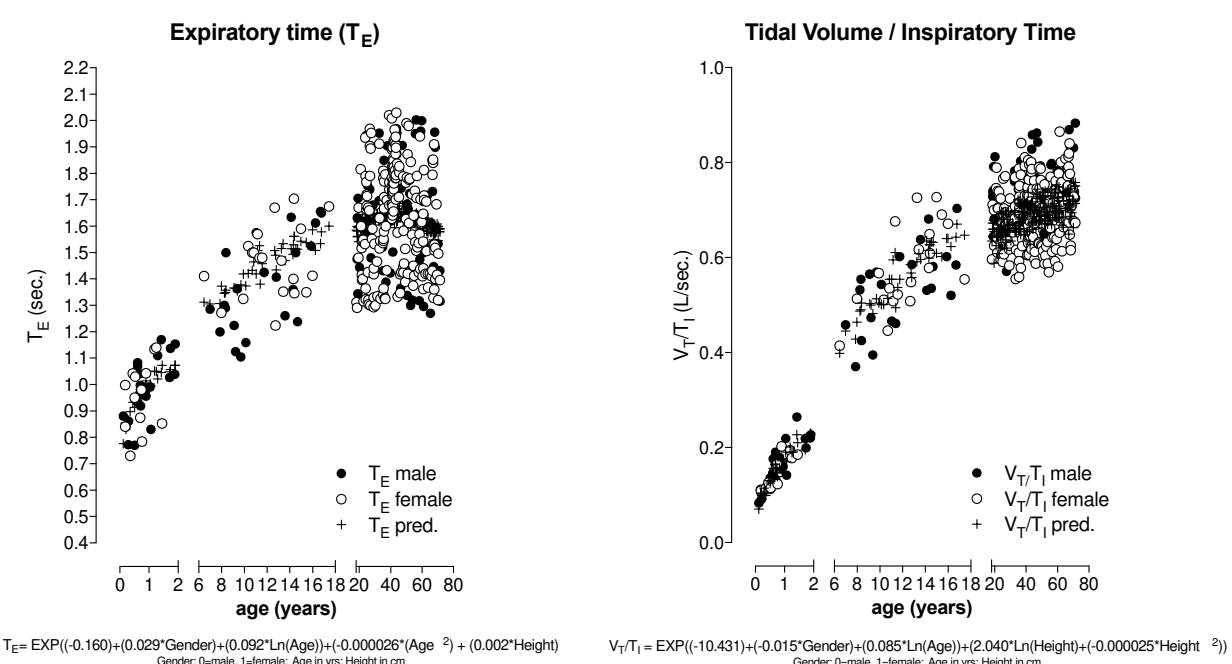
254

255

256

257

\section{$\mathbf{V}_{\mathrm{T}}$ as function of $\mathrm{T}_{\mathrm{I}}$}

stratified according to three $\mathrm{V}_{\mathrm{T}}-\mathrm{T}_{\mathrm{i}}$ quartiles
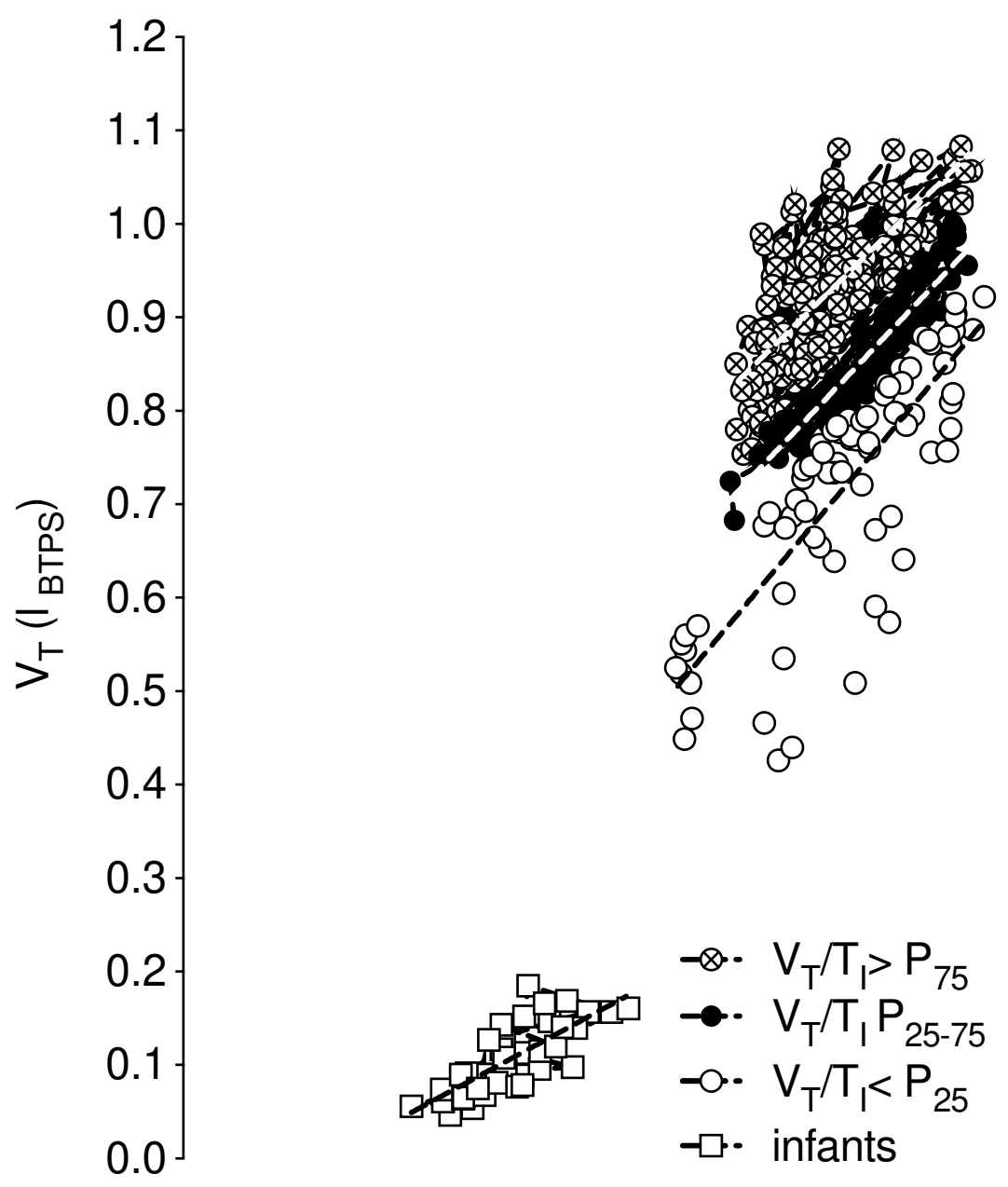

Fig. 3

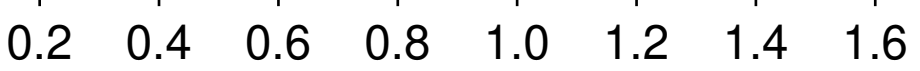


A

Dysanapsis-ratio

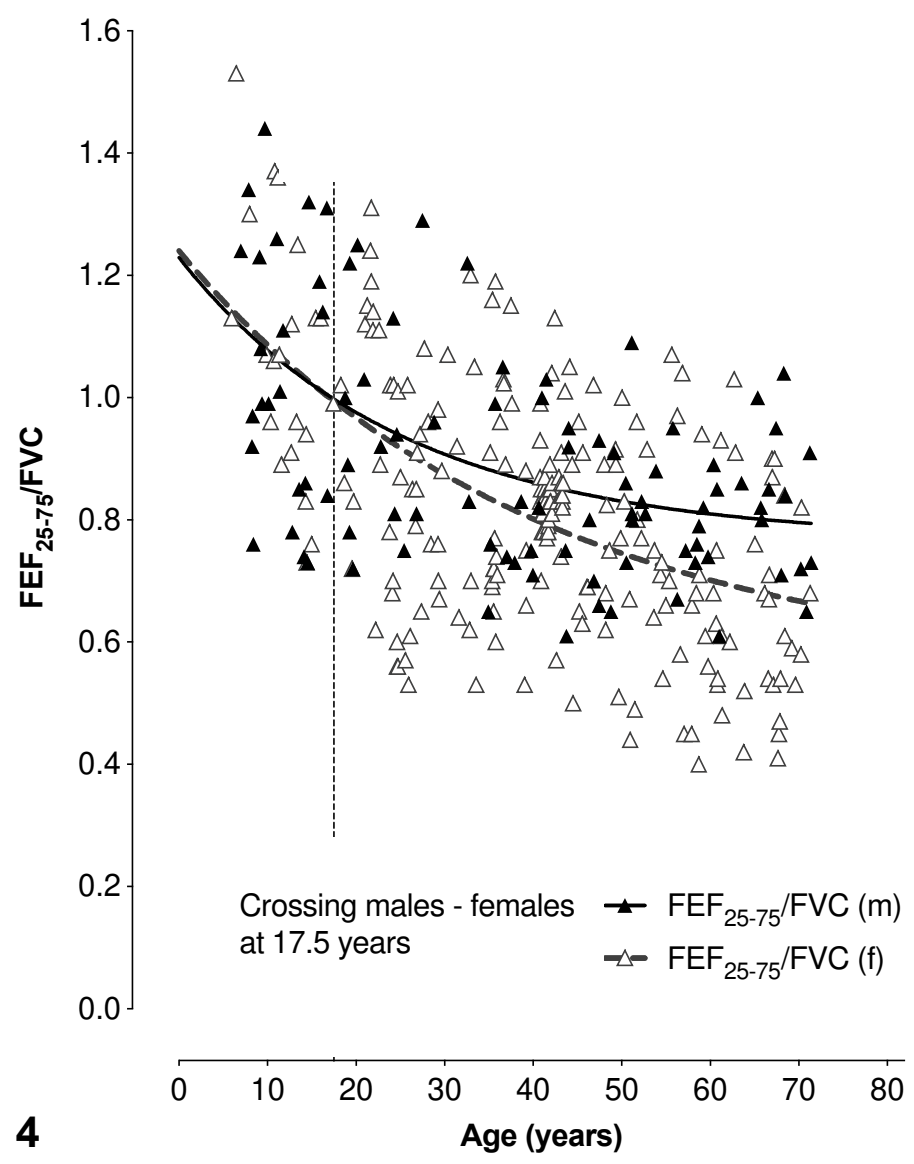
Age (years)
B

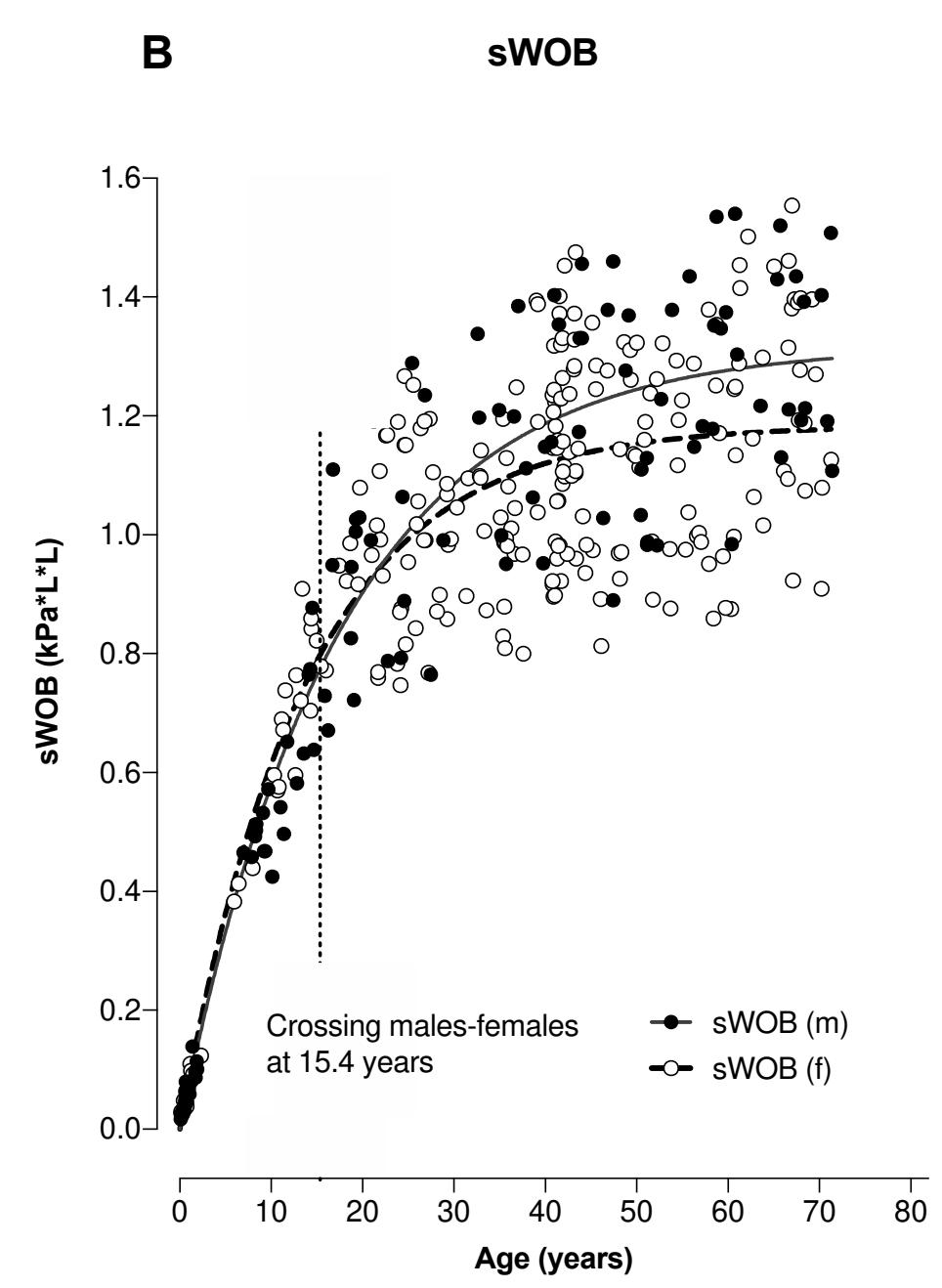

Fig. 4 
A Dysanapsis-ratios

in relation to $\mathrm{FRC}_{\text {pleth }}$ in men and women

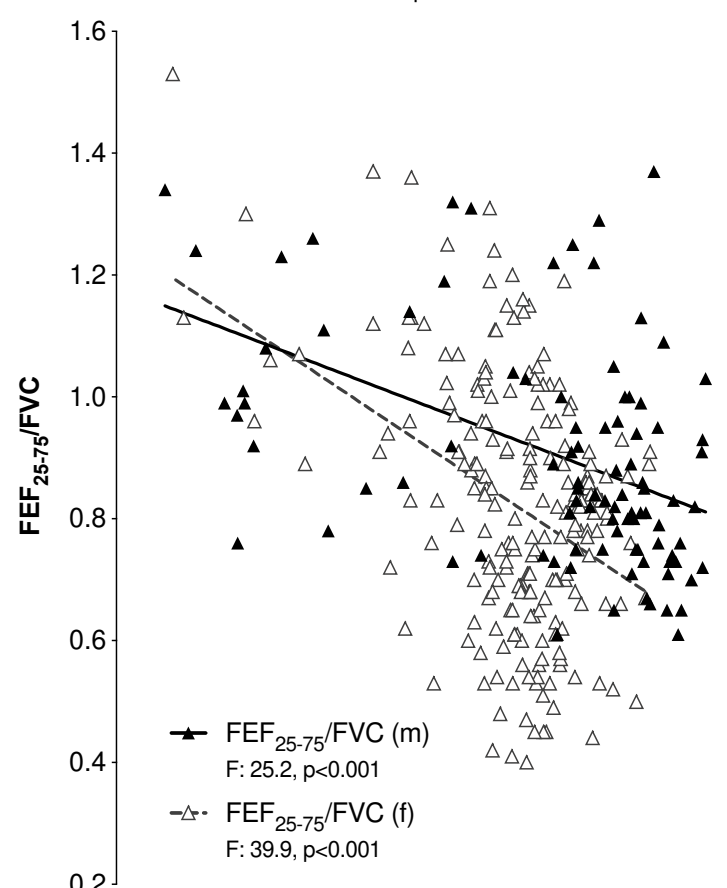

Fig. 5
B Resistive work of breathing

in relation to $F R C_{\text {pleth }}$ in men and women

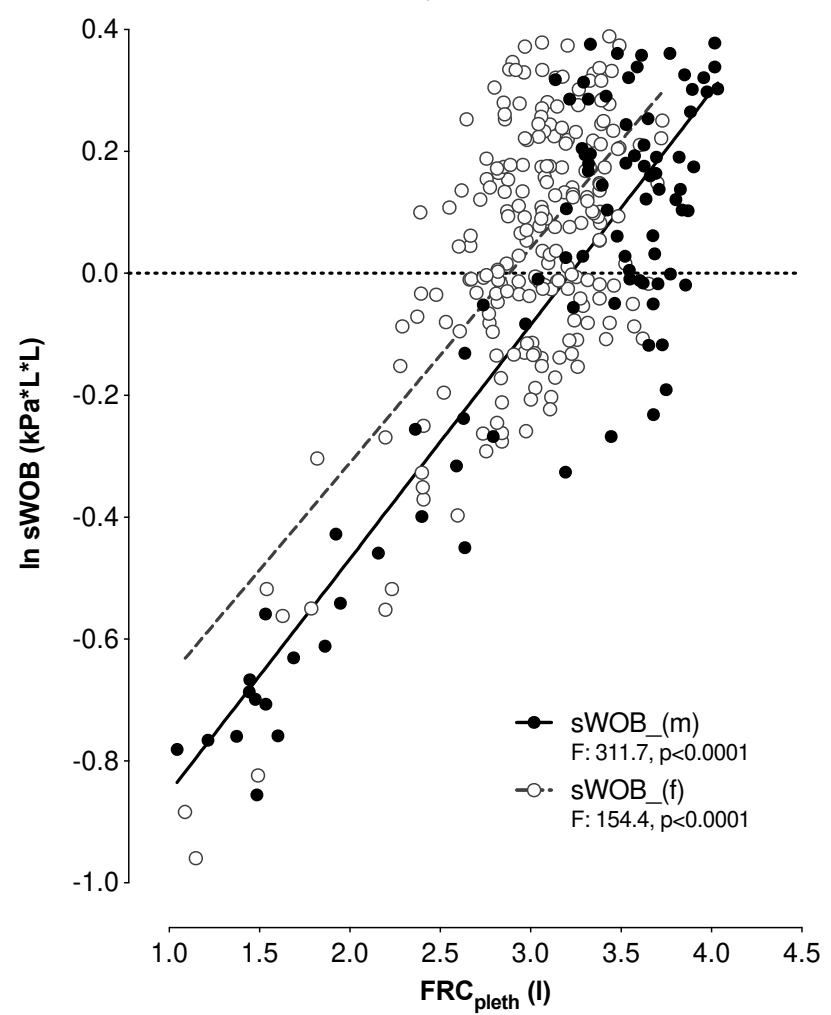




\section{Figures}

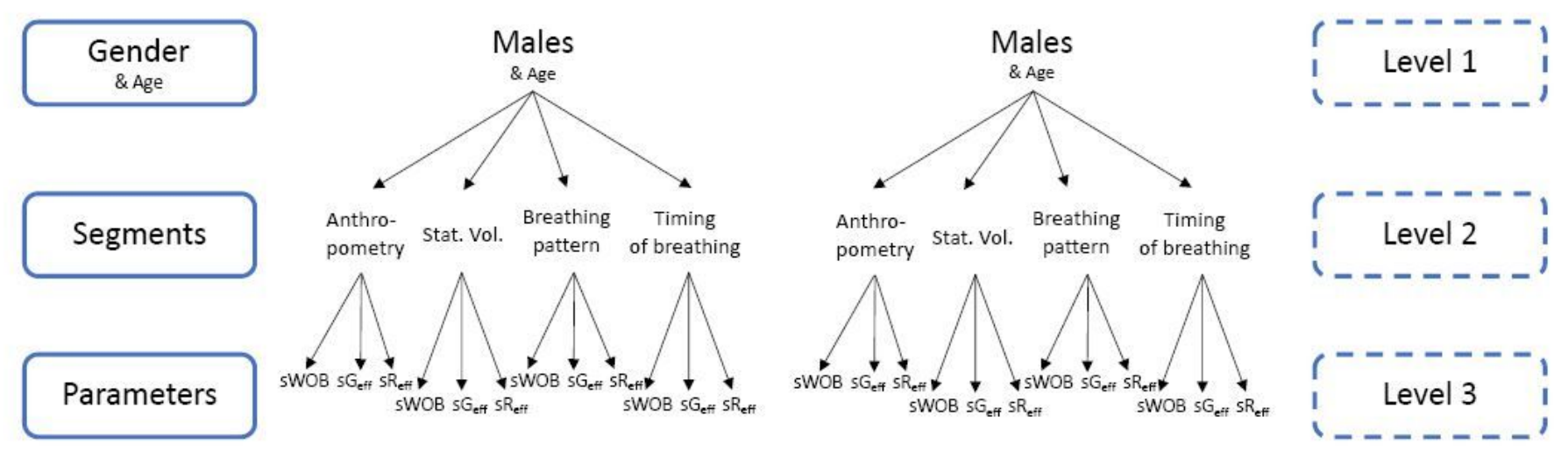

Figure 1

\section{Figure 1}

Modified print-screen, originally depicted from the Jaeger infant whole-body plethysmograph, showing breath-by-breath tracings from which the effective specific airway resistance (sReff), its reciprocal value of the effective specific airway conductance (sGeff) can be computed, using the integral of the tidal flowvolume area $(A)$ and the integral of the plethysmographic shift-volume versus tidal volume area $(B)$, the latter representing the specific aerodynamic work of breathing (sWOB), the crossbar and zero-flow point demonstrating BTPS conditions. sReff) and its reciprocal value, sGeff are computed by the integration of sWOB in relation to the tidal flow-volume loop (C). 

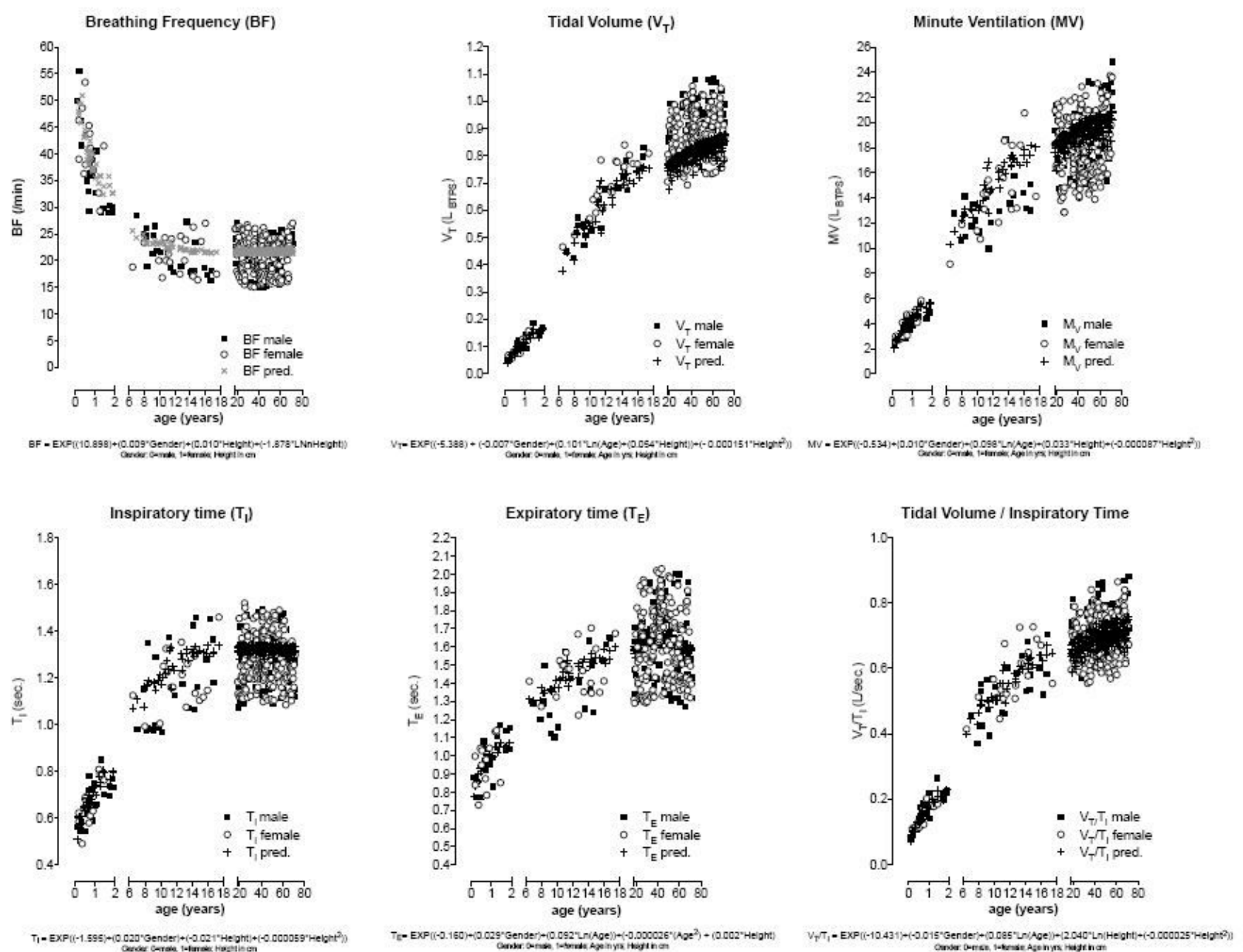

Figure 2

Figure 2

The breathing pattern and timing of breathing transitionally evaluated from infancy, over childhood into adulthood featuring normative predictive equations for the breathing frequency (BF), tidal volume at endexpiratory level (VT), minute ventilation (MV), inspiratory time (TI), expiratory time (TE), and the ratio between VT and TI (VT/TI). 


\section{$V_{T}$ as function of $T_{\text {I }}$ \\ stratified according three $\mathrm{V}_{\mathrm{T}}-\mathrm{T}_{\mathrm{i}}$ quartiles}
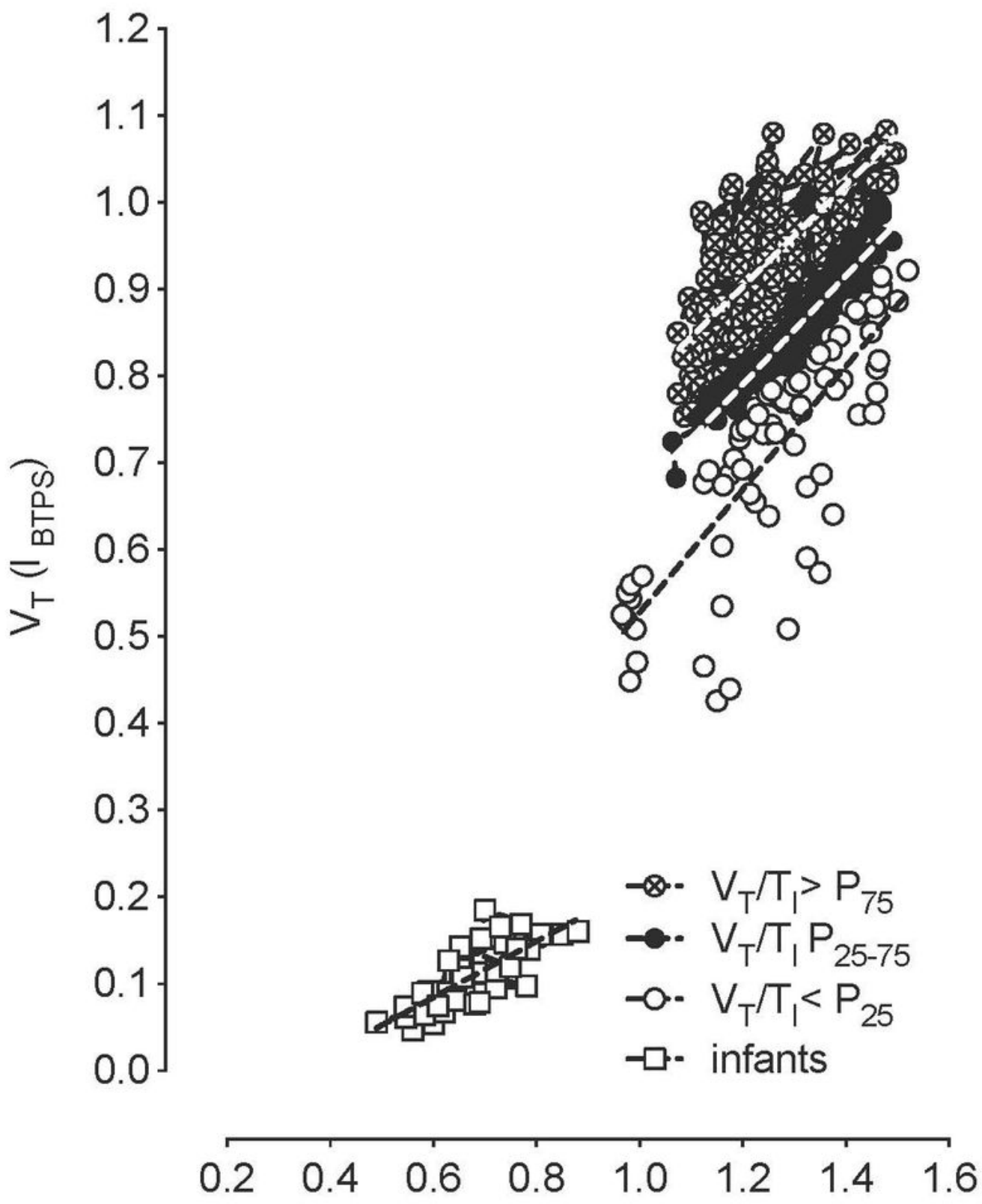

Figure 3

$$
\mathrm{T}_{\mathrm{I}} \text { (sec) }
$$

Figure 3

Tidal volume (VT) as function of inspiratory time (TI) within quartiles of VT/TI at rest. 
A

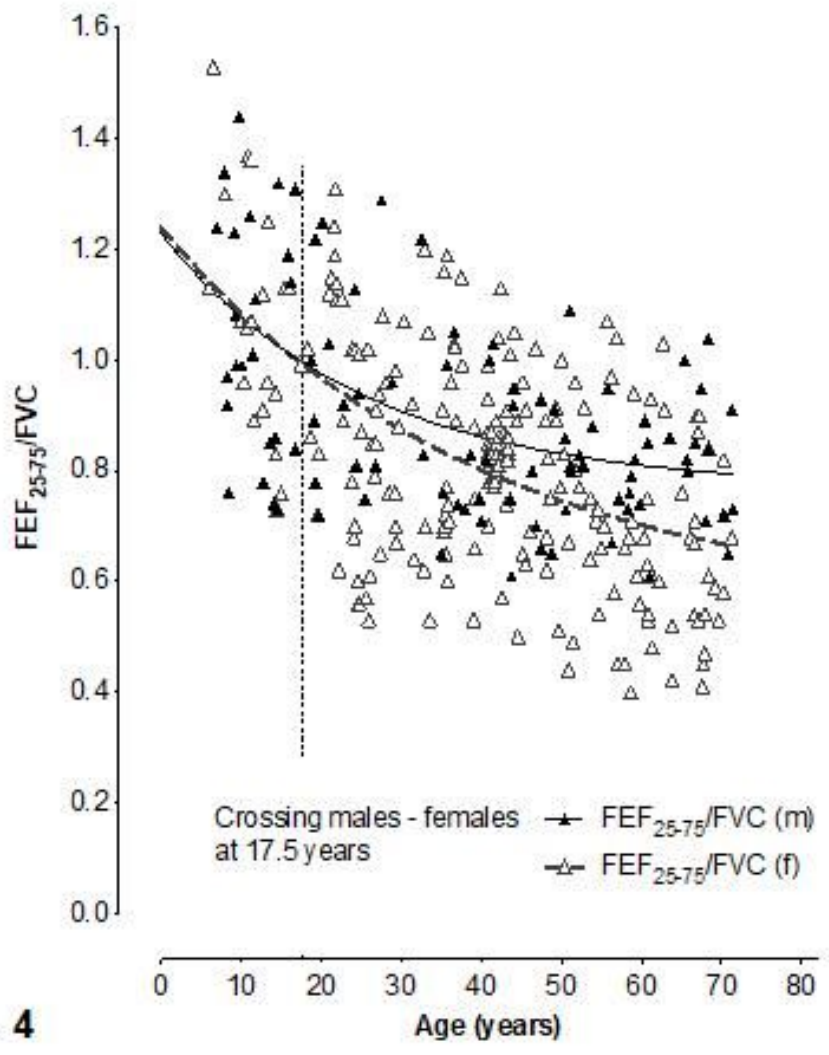

B sWOB

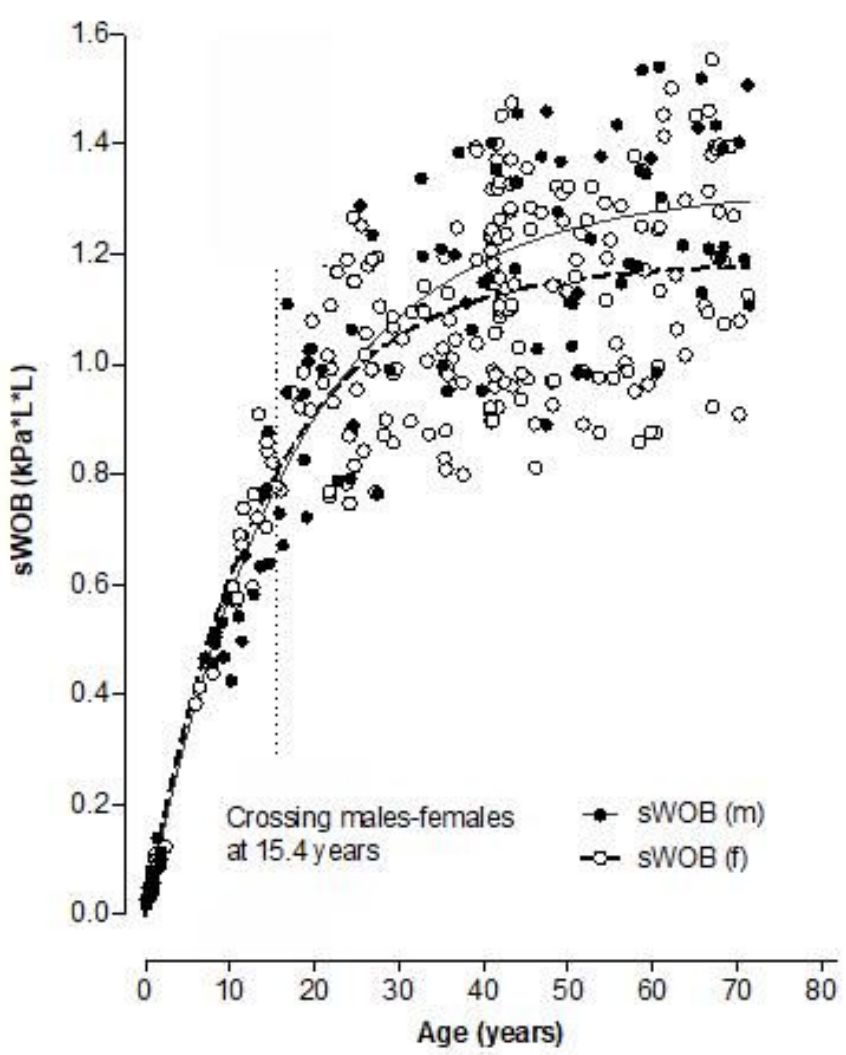

\section{Figure 4}

Relationship between the dysanapsis-ratios FEF25-75/FVC to age (Figure 4A) showing a lower dysanapsis-ratio in females than males after the age of 17.5 years. Similarly, sWOB (Figure 4B) showing a dissociation between males and females, with lower sWOB in females than males after the age of 15.4 years. 

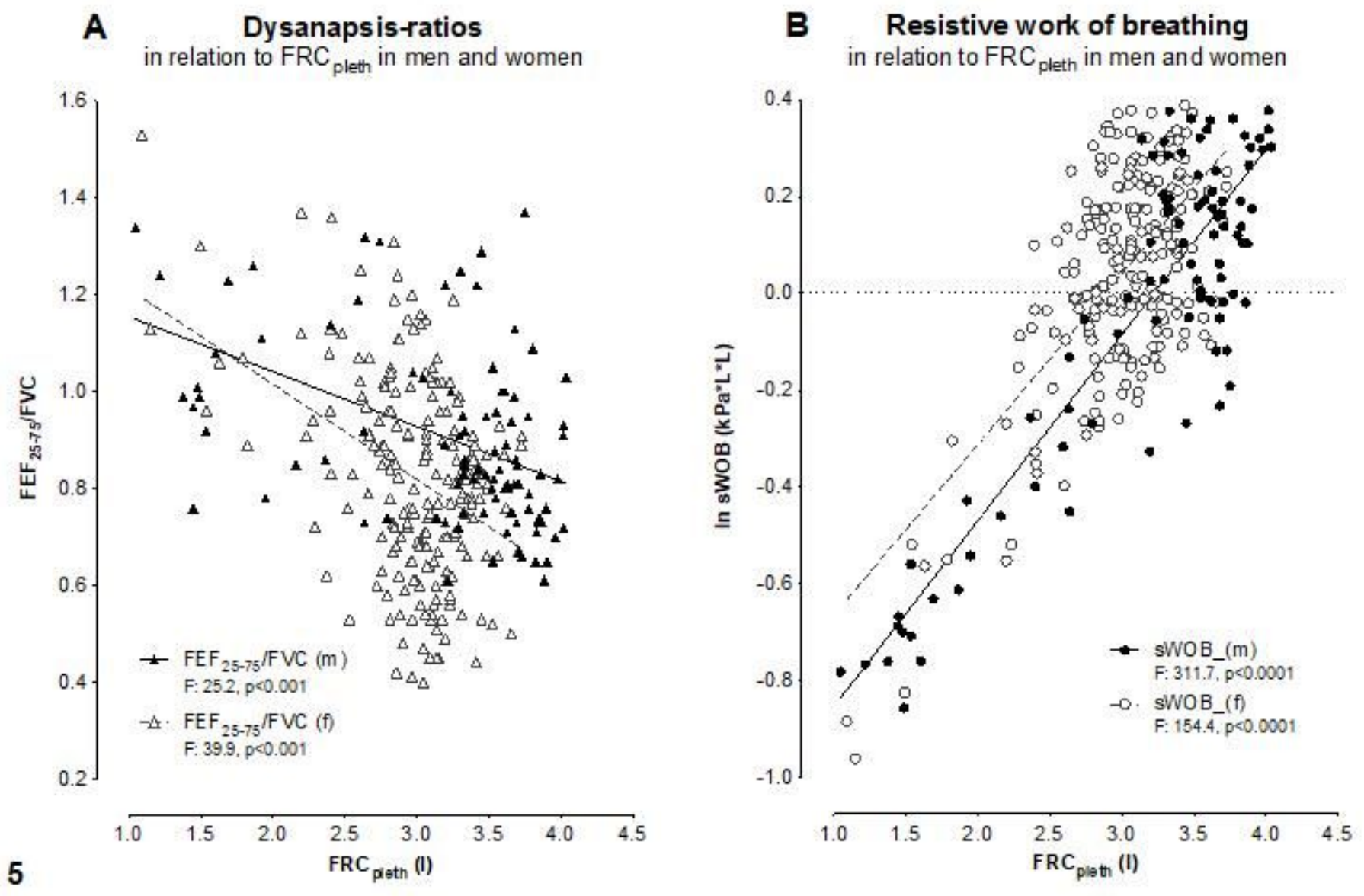

Fig. 5

Figure 5

Dysanapsis given by the dysanapsis-ratio (FEF25-75/FVC) in relation to FRCpleth (Figure 5A) and given by the specific aerodynamic work of breathing (sWOB; Figure5B) both at rest and stratified by gender.

\section{Supplementary Files}

This is a list of supplementary files associated with this preprint. Click to download.

- AdditionalFile1.docx 